\title{
STUDI PERENCANAAN TEBAL PERKERASAN KONSTRUKSI JALAN RAYA PADA RUAS JALAN UMASUKAER DI KABUPATEN MALAKA
}

\author{
$1^{1 *}$ Philipus Resato Nahak, ${ }^{2}$ Yosef Cahyo S.P, ${ }^{3}$ Sigit Winarto \\ Fakultas Teknik Universitas Kadiri \\ email: ${ }^{*}$ philipus@gmail.com, ${ }^{2}$ yosef.cs@unik-kediri.ac.id, ${ }^{3}$ sigit.winarto@unik-kediri.ac.id
}

\begin{abstract}
The increase in traffic volume will cause a decrease in service due to decreased road capacity due to an increase in side constraints and due to the increase in traffic volume itself, which will ultimately cause the level of road saturation to increase. The situation occurred in the Umasukaer road section of the Malacca Regency. Therefore it is necessary to address improvements in the quality of the road in order to meet the feasibility of transportation facilities by taking into account the existing technical requirements. The results of planning found that through the 2015 LHR survey data with a prediction of an increase in traffic density of 6\% per year, the LHR was obtained with a planned age of 7 years $=2540.7$ vehicles/day/department and a 20-year plan life $L H R=5419.1 \mathrm{ked} /$ day $/$ major. The results of a gradual construction planning pavement study can be concluded that the planning model that has been designed is effective in strengthening road construction in accordance with existing technical requirements and efficient in terms of financing. The final results of gradual construction pavement thickness results are: Ashburton thickness $(M S 744)=8 \mathrm{~cm}$, Ashburton $(M S 744)=13 \mathrm{~cm}$, broken stone $(C B R$ 100 $)=20 \mathrm{~cm}$, Sirtu $(C B R 50)=10 \mathrm{~cm}$ and CBR subgrade $5 \%$.
\end{abstract}

Keywords $\quad$ : Pavement Thickness, Highway, Bina Marga, Traffic

\begin{abstract}
ABSTRAK
Pertambahan volume lalu lintas akan menyebabkan penurunan layanan diakibatkan menurunnya kapasitas jalan karena adanya peningkatan hambatan samping maupun karena beratambahnya volume lalu lintas itu sendiri yang pada akhirnya akan meyebabkan tingkat kejenuhan jalan meningkat. Keadaan tersebut terjadi ruas jalan Umasukaer Kabupaten Malaka, oleh karena itu perlu adanya penanganan perbaikan kualitas jalan agar memenuhi segi kelayakan sarana transportasi dengan memperhatikan syarat-syarat teknik yang ada. Hasil perencanaan didapatkan bahwa melalui data survey LHR tahun 2015 dengan prediksi peningkatan kepadatan lalu lintas sebesar 6\% pertahun maka didapatkan LHR dengan umur rencana 7 tahun $=2540,7 \mathrm{kend} / \mathrm{hr} / \mathrm{jurusan}$ dan LHR umur rencana 20 tahun $=5419,1 \mathrm{ked} / \mathrm{hr} /$ jurusan. Hasil studi perencanaan perkerasan konstruksi bertahap dapat diambil kesimpulan bahwa model perencaaan yang telah dirancang efektif dalam memperkerasa konstruksi jalan sesuai dengan syarat teknis yang ada serta efisien dalam hal pembiayaan. Hasil akhir tebal perkerasan konstruksi bertahap diperoleh hasil: Ketebalan Asbuton (MS 744) $=8 \mathrm{~cm}$, Asbuton (MS 744) $=13$ $\mathrm{cm}$, batu pecah $($ CBR 100 $)=20 \mathrm{~cm}$, Sirtu $($ CBR 50) $=10 \mathrm{~cm}$ dan CBR tanah dasar 5\%.
\end{abstract}

Kata Kunci : Tebal Perkerasan, Jalan Raya, Bina Marga, Lalu Lintas 


\section{PENDAHULUAN}

Perkerasan jalan adalah merupakan salah satu unsur kontruksi jalan raya sangat penting dalam rangka kelancaran transportasi darat sehingga memberikan kenyamanan dan keamanan bagi pengugannya, sehingga perlu direncanakan dengan baik berdasarkan standart dan kriterial perencanaan yang berlaku di Indonesia [1][2][3]. Jalan merupakan prasarana transportasi darat yang paling banyak digunakan oleh masyarakat untuk melakukan mobilitas keseharian dibandingkan dengan transportasi air dan udara, sehingga volume kendaraan yang melewati ruas jalan tersebut harus mampu di dukung oleh perkerasan jalan pada ruas jalan yang dilewatinya [4][5][6]. Seperti yang diketahui bahwa sekarang ini pada jalan - jalan dengan volume lalu lintas yang tinggi atau yang melayani kendaraan berat, penurunan umumnya di tandai dengan terjadinya kerusakan strucural seperti terjadinya penyempitan jalan, penurunan alur roda, kriting ( corrugation ) jembul [7][8][9].

Dan jenis kerusakan lainnya. Sedangkan pada jalan - jalan volume lalu lintas rendah di tandai dengan kerusakan - kerusakan yang umumnya di akibatkan oleh suhu maupun lingkungan, [10][11]. Selain itu dengan berkembangnya suatu kawasan, hal ini akan mempunyai pengaruh terhadap tingkat layanan jalan tersebut [12][13][14]. Pertambahan volume lalu lintas akan menyebabkan penurunan layanan karena di akibatkan oleh menurunnya kapasitas jalan karena adanya peningkatan hambatan samping maupun karena beratambahnya volume lalu lintas itu sendiri yang pada akhirnya akan meyebabkan tingkat kejenuhan jalan meningkatkan. Kondisi itu terjadi pada ruas jalan umasukaer ( kabupaten malaka ).

\section{METODE PENELITIAN}

\subsection{Jalan Raya}

Jalan raya adalah jalur tanah di atas permukaan bumi yang dibuat oleh manusia dengan bentuk, ukuran-ukuran dan jenis konstruksi nya sehingga dapat digunakan untuk menyalurkan lalu lintas orang, hewan dan kendaraan yang mengangkut barang dari suatu tempat ke tempat lainnya dengan mudah dan cepat, [1][15]. Untuk perencanaan jalan raya yang baik, bentuk geometris harus diatur sedemikian rupa sehingga jalan yang bersangkutan dapat memberikan layanan optimal untuk lalu lintas sesuai dengan fungsinya, karena tujuan akhir dari rencana geometrik ini adalah untuk menghasilkan infrastruktur yang aman, layanan arus lalu lintas yang efisien dan memaksimalkan rasio tingkat penggunaan biaya dan juga memberikan rasa aman dan nyaman bagi pengguna jalan, [16][17]. 


\subsection{Tipe Konstruksi Perkerasan Jalan}

Ditinjau dari bahan pengikatnya, konstruksi perkerasan dapat dibedakan menjadi:

a. Konstruksi perkerasan lentur (flexible pavement), adalah perkerasan dengan menggunakan bahan berupa aspal sebagai bahan pengikat untuk menahan lapisan pengerasan serta menyebarkan beban kendaraan, [1][18].

b. Konstruksi perkerasan lentur, adalah perkerasan dengan menggunakan aspal sebagai bahan pengkat untuk menahan lapisan pengerasan dan menyebarkan beban kendaraan.

c. Konstruksi perkerasan kaku (regid pavement), adalah perkerasan dengan menggunakan bahan semen (Portland Cement) sebagai bahan pengikat. Sebuah plat beton dengan ataupun tanpa tulang ditempatkan diatas tanah dasar dengan atau tanpa lapis pondasi bawah. Sebagian besar beban lalu lintas ditanggung oleh pelat beton, [11][19].

d. Konstuksi perkerasan komposit (Composite Pavement), adalah perkerasan kaku yang dikombinasikan perkerasan lentur yang dapat berupa perkerasan lentur diatas perkerasan kaku ataupun sebaliknya perkerasan kaku diatas perkerasan lentur.

Tabel 1. Perbedaan Perkerasan Lentur Dan Perkerasan Kaku.

\begin{tabular}{|l|l|l|l|}
\hline \multicolumn{2}{|l|}{} & Perkerasan Lentur & Perkerasan Kaku \\
\hline 1 & Pengikat & Aspal & Semen \\
\hline 2 & Repetise beban & $\begin{array}{l}\text { Timbul rutting } \\
\text { (Lendupan jalur roda) }\end{array}$ & Timbul retak pada permukaan. \\
\hline 3 & $\begin{array}{l}\text { Penurunan tanah } \\
\text { dasar }\end{array}$ & $\begin{array}{l}\text { Jalan bergelombang } \\
\text { (mengikuti kontur dasar ). }\end{array}$ & Bersifat sebagai balok \\
\hline 4 & $\begin{array}{l}\text { Perubahan } \\
\text { Temperator }\end{array}$ & $\begin{array}{l}\text { Modulus kehalusan berubah } \\
\text { timbul tegangan dalam yang } \\
\text { kecil }\end{array}$ & $\begin{array}{l}\text { Modulus kekakuan tidak } \\
\text { berubah timbul tegangan } \\
\text { dalam yang besar . }\end{array}$ \\
\hline
\end{tabular}

Sumber : Buku Perkerasan Lentur Jalan Raya

\subsection{Metode Bina Marga}

Metode Bina Marga adalah versi modifikasi metode AASHTO 1972 yang telah direvisi tahun 1983. Modifikasi tersebut dilakukan sebagai bentuk penyesuaian dengan kondisi alam, lingkungan, sifat tanah dasar dan jenis lapisan perkerasan yang umum dan cocok untuk digunakan di Indonesia, [20][21][22].

a. Bidang Bina Marga mempunyai tugas salah satunya melaksanakan sebagian tugas kepala dinas pekerjaan umum di Bidang Marga.

b. Dalam melaksanakan tugas yang dimaksud ayat (1), Bidang Bina Marga memiliki fungsi:

1) Menyusun rencana teknis, progam pembinaan dan bimbingan teknis Bina Marga.

2) Pengawasan, pengendalian dan pelaksanaan perkerjaan Bina Marga. 
3) Perijinan dan pengawasan dari pemanfaatan jalan berserta kegunaannya.

4) Penanggulangan jalan dan jembatan akibat bencana alam.

5) Pengumpulan data Bidang Bina Marga.

6) Pelaksanaan tugas lain yang telah diberikan kepala dinas.

\subsection{Lokasi Studi Kasus}

Lokasi yang menjadi obyek studi kasus yang dipilih pada penulisan tugas akhir ini adalah perencanaan tebal perkerasan jalan Umasukaer (Di Kabupaten Malaka Nusa Tengara Timur).

\subsection{Tahapan Persiapan}

Tahap persiapan adalah rangkaian kegiatan sebelum melasanakan proses pengumpulan dan pengolahan data. Pada tahap awal ini disusunlah hal-hal penting yang harus dilakukan dengan tujuan meningkatkan efektifitas waktu dan kerja. Tahap persiapan meliputi:

a. Studi pustaka terkait materi tugas akhir dengan tujuan menentukan garis besar permasalahan.

b. Menentukan kebutuhan data yang digunakan.

c. Mencari informasi melalui instansi terkait yang dapat dijadikan bahan pelengkap.

d. Survei pada lokasi penelitian untuk mendapat gambaran umum kondisi proyek

e. Perencanaan kondisi pembuatan desain.

\subsection{Metode Pengumpulan Data}

Data yang digunakan untuk mendukung penyusunan tugas akhir ini diperoleh dari proyek pembangunan Jalan Umasukaer (Kabupaten Malaka Nusa Tenggarah Timur). Sebagai data sekunder antara lain :

a. Data lapangan

b. Peta lokasi dan trase jalan.

c. Rata-rata jumlah lalu-lintas harian, yaitu berkaitan dengan jenis dan volume kendaraan yang melewati jalan tersebut.

d. Peraturan tentang perancangan perkerasan jalan.

\subsection{Analisa Dan Pengolahan Data}

Analisa dan pengolahan data dilakukan berdasarkan data data yang dibutuhkan, selanjutnya dikelompokkan sesuai identifikasih permasalahan, sehingga di peroleh penganalisaan pemecahan yang efektif dan tearah. Data yang di peroleh kemudian akan digunakan untuk perencanaan perkerasan jalan, adapun analisa data tersebut adalah sebagi berikut: Analisa lalulintas, Analisa kondisi jalan, Perencaan tebal perkerasan dan Analisa geometrik jalan. 


\section{PERENCANAAN DAN PEMBAHASAN}

\subsection{Data Survey Rencana Jalan}

Pada dasarnya survey yang dilakukan pada perencanaan ini adalah berupa survey kelayakan stiuktural konstruksi perkerasan secara non konstruktif, yaitu suatu cara pemeriksaan dengan menggunakan alat (Benkelman Beam) yang diletakkan dialas permukaan jalan sehingga tidak berakibat rusaknya konstruksi perkerasan jalan. Data-data tersebut antara lain:

a. Data lalu lintas diperlukan untuk perencanaan tehal perkerasan jalan dari geometrik jalan. Dalam hal ini data lalu lintas yang diperoleh dari Dinas Pekerjaan Umum Daerah Tingkat I Nusa Tenggara Timur.

b. Data lalu lintas (2 jalur) yang diamati pada bulan Desember 2015 dengan curah hujan $<900$ mm/tahun, membagi jenis kendaraan menjadi sebelas golongan. Hasil Core Drill dilapangan dilakukan pengamatan secara visual, maka direncanakan perkerasan konstruksi bertahap dengan rencana jalan dibuka pada tahun 2019 dan selama pelaksanaan perkembangan Lalu lintas (i) $=6 \%$ per tahun.

Tabel 2. Data Lalu Lintas Harian Rata-Rata (LHR) 2015

\begin{tabular}{|l|l|l|}
\hline No & Jenis Kendaraan & LHR \\
\hline 1 & Sepida motor, kendaraan roda tiga & 3253 \\
\hline 2 & Sedan, jeep dan station wagon & 2561 \\
\hline 3 & Oplct. combi dan minibus & 1000 \\
\hline 4 & Pick-up, mikro truck & 934 \\
\hline 5 & Bus kccil & 32 \\
\hline 6 & Bus besar & 300 \\
\hline 7 & Truck 2 sumbu & 50 \\
\hline 8 & Truck 3 sumbu & 30 \\
\hline 9 & Track gandengan & 10 \\
\hline 10 & Track semi trailer & 6 \\
\hline 11 & Kendaraan tak bermotor & 1289 \\
\hline
\end{tabular}

Sumber: Dinas PU Bina Marga Daerah Tingkat I Nusa Tenggara Timur

Untuk memperoleh data volume lalu lintas yang dinyatakan dalam Satuan Mobil Penumpang (SMP), nilainya menunjukkan jumlah lalu lintas harian rata-rata untuk kedua jurusan, maka digunakanlah koeflsien dibawah ini yang dikalikan jenis kendaraan yang bersangkutan.

Tabel 3. Data Volume lalu lintas (VLL)

\begin{tabular}{|l|l|l|l|}
\hline No & LHR & Koefisien & VLL \\
\hline
\end{tabular}




\begin{tabular}{|r|c|c|c|}
\hline 1 & 4523 & 1 & 3253 \\
\hline 2 & 3631 & 1 & 2561 \\
\hline 3 & 1000 & 2 & 2000 \\
\hline 4 & 1232 & 2 & 1868 \\
\hline 5 & 25 & 3 & 96 \\
\hline 6 & 300 & 3 & 900 \\
\hline 7 & 50 & 3 & 150 \\
\hline 8 & 30 & 3 & 90 \\
\hline 9 & 10 & 3 & 30 \\
\hline 10 & 4 & 3 & 18 \\
\hline 11 & 1532 & 7 & 9023 \\
\hline
\end{tabular}

Sumber: Dinas PU Bina Marga Daerah Tingkat I Nusa Tenggara Timur

\subsection{Perhitungan Tebal Perkerasan Konstruksi Bertahap}

a. Perhitungan Nilai CBR

Tabel 4. Nilai Rencana CBR Rencana

\begin{tabular}{|r|c|c|l|}
\hline No & CBR & Jumlah yang & Prosentase (\%) yang sama atau lebih besar \\
\hline 1 & 4 & 10 & $10 / 10 \times 100 \%=100 \%$ \\
\hline 2 & 5 & 9 & $9 / 10 \times 100 \%=90 \%$ \\
\hline 3 & 6 & 8 & $8 / 10 \times 100 \%=80 \%$ \\
\hline 4 & 7 & 7 & $7 / 10 \times 100 \%=70 \%$ \\
\hline 5 & 7 & - & - \\
\hline 6 & 7 & - & - \\
\hline 7 & 7 & - & - \\
\hline 8 & 9 & 3 & $3 / 10 \times 100 \%=30 \%$ \\
\hline 9 & 9 & - & - \\
\hline 10 & 11 & 1 & $1 / 10 \times 100 \%=10 \%$ \\
\hline
\end{tabular}

Sumber: Dinas PU Bina Marga Daerah Tingkat I Nusa Tenggara Timur

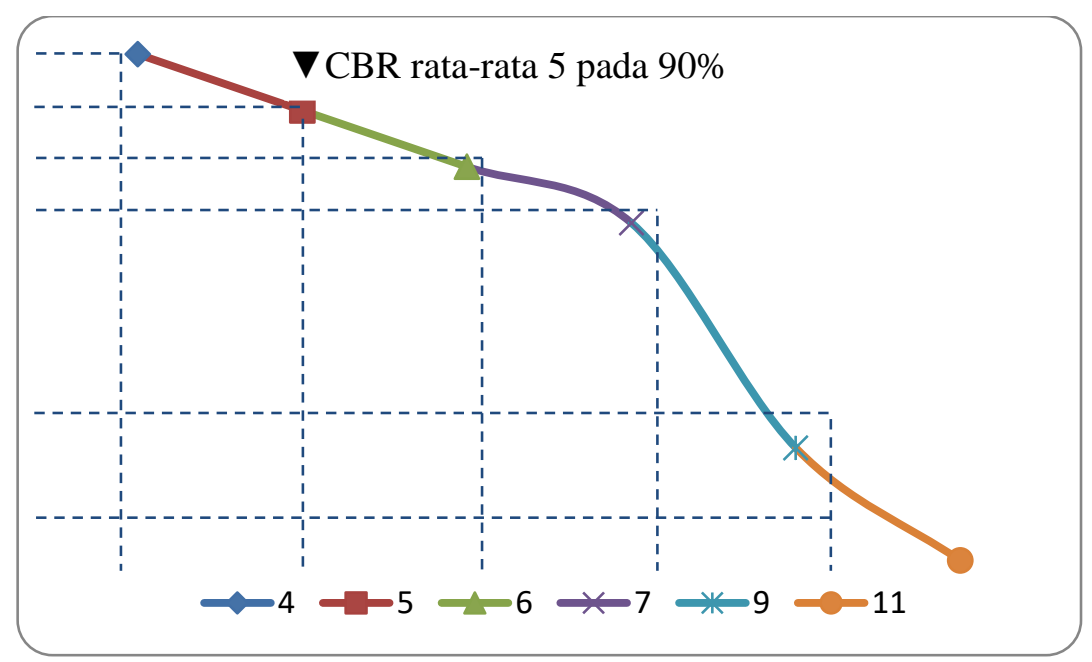

Grafik 1. Penentuan Harga CBR Rata-Rata 
b. Perhitungan LHR Pada Akhir Umur Rencana

1) Bahan-bahan perkerasan yang digunakan

$\begin{array}{lll}\text { Asbuton (MS 744) } & \rightarrow \text { al } & =0,35 \\ - \text { Batu Pecah (CBR 100\%) } & \rightarrow \text { a2 } & =0,14 \\ - \text { Pasir dan batu (CBR 50\%) } & \rightarrow \text { a3 } & =0,12\end{array}$

2) LHR tahun 2013 (awal umur rencana), rumus (l+i)n

$\begin{array}{ll}\text { - Kendaraan ringan } 2 \text { ton }(1+1) & =1215,5 \text { kendaraan } \\ \text { - Bus } 8 \text { ton }(3+4) & =364,7 \text { kendaraan } \\ \text { - Truck } 2 \text { as } 13 \text { ton }(5+8) & =60,8 \text { kendaraan } \\ \text { - Truck } 3 \text { as } 20 \text { ton }(6+7,7) & =36,5 \text { kendaraan } \\ \text { - Truck } 5 \text { as } 30 \text { ton }(6+7,7+5+5) & =12,2 \text { kendaraan }\end{array}$

3) LHR pada tahun ke 7 dan 13 (akhir pentahapan), dengan rumus(l+i)n

7 Tahun

- Kendaraan ringan 2 ton

- Bus 8 ton

- Truck 2 as berat 13 ton

- Truck 3 as berat 20 ton

- Truck 5 as berat 30 ton

\begin{tabular}{rrr} 
& \multicolumn{1}{c}{7 Tahun } & \multicolumn{2}{c}{20 Tahun } \\
$=$ & 1827,7 kendaraan & 3898,3 kendaraan \\
$=$ & 548.4 kendaraan & 1169,6 kendaraan \\
$=$ & 91,4 kendaraan & 195,0 kendaraan \\
$=$ & 54,9 kendaraan & 117,1 kendaraan \\
$\mathrm{LHR}_{7}=$ & 18,3 kendaraan & 39,1 kendaraan \\
\hline
\end{tabular}

4) Ekivalen (E) tiap kendaraan

- Kendaraan ringan 2 ton $(1+1)$

- Bus 8 ton $(3+5)$

- Truck 2 as berat 13 ton $(5+8)$

- Truck 3 as berat 20 ton $(6+7,7)$

$=0,00002+0,00002=0,00004$

$=0.0183+0,1410=0.1593$

$=0,1410+0,9238$

$=0,2923+0,7452$

- Truck 5 as berat 30 ton $(6.7,7+5+5)$

Total $=3,57527$ kendaraan

Perhitungan LEP:

- Kendaraan ringan berat 2 ton

$=0,50 \times 1215.5 \times 0,0004=0,243$

- Bus 8 berat ton

$=0,50 \times 364,7 \times 0,1593=29,046$

- Truck 2 as berat 13 ton

$=0,50 \times 60,8 \times 1,0648=32,370$

- Truck 3 as berat 20 ton

$=0.50 \times 36,5 \times 1,0375=18.934$ 
- Truck 5 as berat 30 ton

$$
\begin{aligned}
& =0.50 \times 12,2 \times 1,3195=8.048 \\
\text { Total } & =88,643 \text { kendaraan }
\end{aligned}
$$

Perhitungan LEA:

- Kendaraan ringan berat 2 ton

$$
\begin{aligned}
& =0.50 \times 1827,7 \times 0,0004=0,366 \\
& =0,50 \times 548,4 \times 0,1593=43,680 \\
& =0,50 \times 91,4 \times 1,0648=48,661 \\
& =0.50 \times 54,9 \times 1,0375=28,479 \\
& =0.50 \times 18,3 \times 1,3195=12,073
\end{aligned}
$$

- Bus berat 8 ton

- Truck 2 as berat 13 ton

- Truck 3 as berat 20 ton

- Truck 5 as berat 30 ton

$$
\text { Total }=133,258 \text { kendaraan }
$$

Dengan nilai CBR 5\% diperoleh DDT $=4,6$ dan IP $=2,0$ dengan $\mathrm{FR}=1,0$

$$
\begin{array}{lll}
1,67 \mathrm{LER}_{7}=129 & \overline{\mathrm{ITP}_{7}}=6,8 & (\text { Ipo }=3,9-3,5) \\
1,67 \mathrm{LER}_{13}=620 & \overline{\mathrm{ITP}_{13}}=8,4 & (\text { Ipo }=3,9-3,5)
\end{array}
$$

5) Perhitungan Tebal Perkerasan: UR (7+13) tahun

$$
\begin{array}{ll}
\text { ITP } & =a 1 \mathrm{D} 1+\mathrm{a} 2 \mathrm{D} 2+\mathrm{a} 3 \mathrm{D} 3 \\
8,4 & =0,35 \mathrm{D} 1+0,14 \times 20+0,12 \times 10 \\
8,4 & =0,35 \mathrm{D} 1+2,8+1,2 \\
8,4 & =0,35 \mathrm{D} 1+4 \\
\text { D1 } & =12,57 \approx 13 \mathrm{~cm} \\
\text { ITP } & =\mathrm{alDl}+\mathrm{a} 2 \mathrm{D} 2+\mathrm{a} 3 \mathrm{D} 3 \\
6,8 & =0,35 \mathrm{D} 1+0,14 \times 20+0.12 \times 10 \\
6,8 & =0,35 \mathrm{D} 1+2.8+1,2 \\
6,8 & =0,35 \mathrm{D} 1+4 \\
\text { D1 } & =8 \mathrm{~cm} .
\end{array}
$$

6) Rencana Perkerasan

$$
\begin{array}{ll}
\text { Asbuton (MS 744) } & =8 \mathrm{~cm} \\
\text { Asbuton (MS 744) } & =13 \mathrm{~cm} \\
\text { Batu Pecah (CBR 100) } & =20 \mathrm{~cm} \\
\text { Pasir dan batu (CBR 50) } & =10 \mathrm{~cm} .
\end{array}
$$

\subsection{Perhitungan Geometri Jalan}

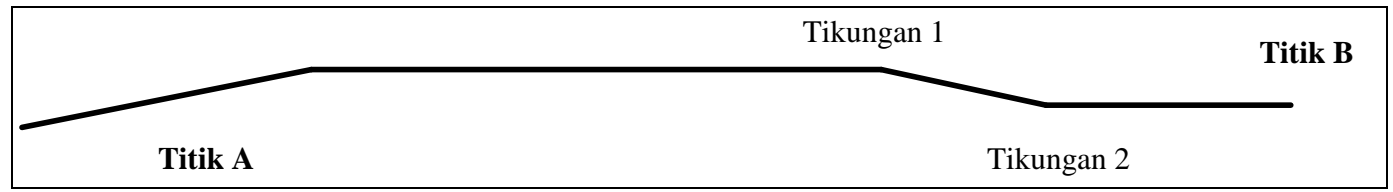

Gambar 1. Trase Rencana Jalan Klasifikasi Jalan 
Maka di dapatkan nilai koordinat, jarak, azimuth, dan sudut tikungan seperti yang dijabarkan pada tabel dibawah ini:

Tabel 4. Nilai Koordinat, Jarak, Azimuth, Dan Sudut Tikungan

\begin{tabular}{|c|c|c|c|c|c|c|c|c|c|c|}
\hline \multirow{2}{*}{ Koordinat } & \multirow{2}{*}{$x$} & \multirow{2}{*}{ Y } & $d C-1$ & $d 1-2$ & d2 $2 \cdot H$ & \multirow{2}{*}{ X Azimuth } & \multirow{2}{*}{ Y Azimuth } & $\operatorname{TAN}(-1)$ & AZIMUTH & D (DELTA) \\
\hline & & & (m) & (m) & (m) & & & $(0)$ & 101 & (0) \\
\hline TitikC & 9966,250 & 9878,750 & \multirow{2}{*}{171,291} & & & $-166,250$ & $-41,250$ & 76,060 & 13,940 & \\
\hline Titik1 & 10132,500 & 9920,000 & & \multirow{2}{*}{345,778} & & $-342,500$ & 47,500 & $-82,100$ & 7,900 & 21,840 \\
\hline Titik 2 & 10475,000 & 9872,500 & & & \multirow{2}{*}{251,486} & $-213,750$ & $-132,500$ & 58,210 & 31,790 & 39,690 \\
\hline TitikH & 10688,750 & 10005,000 & & & & & & & & \\
\hline
\end{tabular}

Tabel 5. Klasifikasi Medan Jalan

\begin{tabular}{|c|c|c|c|c|c|c|}
\hline \multirow{3}{*}{ Titik } & \multicolumn{3}{|c|}{ Ketinggian } & \multirow{3}{*}{$\begin{array}{l}\text { Elevasi } \\
\text { Kanan }\end{array}$} & \multirow{3}{*}{ Elevasi Kiri } & \multirow{3}{*}{ Kemiringan $(\%)$} \\
\hline & \multicolumn{3}{|c|}{$(\mathrm{m})$} & & & \\
\hline & Kanan & Kiri & As & & & \\
\hline B & 95.63 & 95.72 & 95,68 & 95,65 & 95,73 & 0,2 \\
\hline 1 & 95.25 & 95.40 & 95,34 & 95,27 & 95,45 & 0,45 \\
\hline 2 & 95.20 & 95.10 & 95,15 & 95,22 & 95,13 & 0,225 \\
\hline $\mathrm{H}$ & 93.40 & 93.40 & 93,40 & 93,40 & 93,40 & 0 \\
\hline \multicolumn{6}{|c|}{ Rata - Rata } & 0,35 \\
\hline
\end{tabular}

Didapatkan nilai rata-rata kemiringan pada lokasi direncanakannya jalan adalah $0,35 \%$, menurut Tata Cara Perencanaan Geometrik Jalan Antar Kota Departemen Pekerjaan Umum tahun 1997 bila kemiringan<3\% maka disimpulkan medan pada lokasi perencanaan geometrik jalan ini adalah datar.

\section{KESIMPULAN}

1. Dari data Survey LHR 2009 dengan prediksi pertumbuhan Lalu-lintas 6\% pertahun, maka didapatkan LHR umur rencana 7 tahun $=2540,7 \mathrm{kcnd} / \mathrm{hr} / 2 \mathrm{jurusan}$ dan LHR umur rencana 20 tahun $=5419,1 \mathrm{kend} / \mathrm{hr} / \mathrm{jurusan}$.

2. Dari hasil Studi Pcrencanaan Perkcrasan Konstruksi Bcrtahap dapat diambil kesimpulan, bahwa Model Perencanaan seperti ini sangat efisien dan efektif karena hanya dengan sckali merencanakan. maka pelaksanaannya dapat dilakukan secara bertahap sehingga dapat disesuaikan dengan biaya yang ada.

\section{UCAPAN TERIMAKASIH}


Dalam penyusunan artikel ini, penulis ucapkan terimakasih kepada dosen pembimbing dan Universitas Kadiri. Penulis berharap agar artikel ini dapat bermanfaat bagi pembaca.

\section{DAFTAR PUSTAKA}

[1] Departemen Pekerjaan Umum, "Petunjuk Perencanaan Tebal Perkerasan Lentur Jalan Raya Dengan Metode Analisa Komponen,” 1987.

[2] A. Kholiq, "Perencanaan Tebal Perkerasan Lentur Jalan Raya Antara Bina Marga Dan Aashto'93 (Studi Kasus: Jalan Lingkar Utara Panyingkiran-Baribis Ajalengka),” J-Ensitec, vol. 1, no. 01, pp. 43-51, 2014, doi: 10.31949/j-ensitec.v1i01.15.

[3] O. Nurahmi and A. A. G. Kartika, "Perbandingan Konstruksi Perkerasan Lentur dan Perkerasan Kaku serta Analisis Ekonominya pada Proyek Pembangunan Jalan Lingkar Mojoagung," J. Tek. ITS, vol. 1, no. 1, pp. 63-68, 2012.

[4] E. Nurfadzilah, S. Winarto, and Y. C. SP, “ANALISA JALAN RING ROAD NGAWI STA 3+200 - STA 6+200 KABUPATEN NGAWI PROPINSI JAWA TIMUR,” Jurmateks, vol. 1, no. 1, pp. 33-43, 2018.

[5] A. Wignall, "Proyek Jalan Teori dan Praktek," 2000.

[6] A. I. Candra, S. Anam, Z. B. Mahardana, and A. D. Cahyono, "STUDI KASUS STABILITAS STRUKTUR TANAH LEMPUNG PADA JALAN TOTOK KEROT KEDIRI MENGGUNAKAN LIMBAH KERTAS," Ukarst J. Univ. Kadiri Ris. Tek. Sipil, vol. 2, no. 2, pp. 88-97, 2018.

[7] B. A. Harsono, S. Winarto, and Y. C. S, "PERENCANAAN PENINGKATAN JALAN PADA RUAS JALAN PACITAN-NGADIROJO,” Jurmateks, vol. 1, no. 2, pp. 291-302, 2018.

[8] E. Gardjito, "STUDY PERENCANAAN GEOMETRIK, PERKERASAN JALAN DAN PERENCANAAN ANGGARAN BIAYA PADA JALAN RAYA KALIDAWIR - Ds. NGUBALAN Kec. KALIDAWIR,” UKaRsT, vol. 1, no. 2, pp. 94-101, 2017, doi: 10.30737/ukarst.v1i2.264.

[9] A. I. Candra, A. Yusuf, and A. R. F, "Studi Analisis Daya Dukung Pondasi Tiang Pada Pembangunan Gedung Lp3M Universitas Kadiri," J. CIVILA, vol. 3, no. 2, p. 166, 2018, doi: 10.30736/cvl.v3i2.259.

[10] C. Yulianto, Y. Cahyo, A. Ridwan, and A. I. Candra, "PENELITIAN PENAMBAHAN BAHAN ADITIF KAPUR PADAM SEBAGAI BAHAN PENGISI FILLER PADA CAMPURAN ASPAL BETON,”Jurmateks, vol. 1, no. 2, pp. 204-215, 2018.

[11] N. A. Affandi and R. Hepiyanto, "Studi Evaluasi Tebal Perkerasan Kaku Pada Ruas Jalan 
Dradah - Kedungpring Mengunakan Metode Bina Marga 2002,” UKaRsT, vol. 2, no. 2, p. 7, 2018, doi: 10.30737/ukarst.v2i2.265.

[12] R. Yuwono, Y. C. Sp, and L. D. K, "STUDY ANALISA VOLUME KENDARAAN PADA SIMPANG BERSINYAL DI PEREMPATAN ALUN ALUN KOTA KEDIRI,” Jurmateks, vol. 1, no. 1, pp. 101-111, 2018.

[13] S. Sukirman, Perkerasan lentur jalan raya, vol. 2. 1999.

[14] I. T. Husodo and S. Budirahardjo, "Analisa desain pelebaran perkerasan lentur pada jalan wolter monginsidi semarang," J. Tek. Sipil Giratory Upgris, vol. 1, no. 1, pp. 1-9, 2019.

[15] H. . H. Hasmar, Drainasi Terapan. Yogyakarta : UII Press, 2011, 2011.

[16] Dinas Pekerjaan Umum dan Penataan Ruang, “Analisa Harga Satuan,” Kediri, 2018.

[17] Departemen Permukiman dan Prasarana Wilayah, "Pd T-14-2003 Perencanaan Perkerasan Jalan Beton Semen.” .

[18] Direktorat Jendral Bina Marga, "Perencanaan Geometrik Jalan," Departemen Pekerjaan Umum. 2017.

[19] [Kementerian PUPR]. Kementerian Pekerjaan Umum dan Perumahan Rakyat, "Perencanaan Perkerasan Jalan Beton Semen,” p. 52, 2003.

[20] Badan Standardisasi Nasional, "SNI 03-2406-1991 Tata Cara Perencanaan Umum Drainase Perkotaan," 1991.

[21] Badan Standardisasi Nasional, "SNI 03-3424-1994 Tata Cara Perencanaan Drainase Permukaan Jalan,” 1994.

[22] Badan Standardisasi Nasional, "SNI 03-1724-1989 Pedoman Perencaanaan Hidrologi dan Hidraulik untuk Bangunan di Sungai,” pp. 1-38, 1989. 